\title{
Hamsa
}

Journal of Judaic and Islamic Studies

$2 \mid 2015$

Varia

\section{Recaudación real y prácticas de poder ejercidas en el siglo XV por recaudadores judíos en Galicia}

\section{María Gloria de Antonio Rubio}

\section{OpenEdition}

1 Journals

\section{Edición electrónica}

URL: https://journals.openedition.org/hamsa/791

DOI: $10.4000 /$ hamsa.791

ISSN: 2183-2633

\section{Editor}

CIDEHUS - Centro Interdisciplinar de História Culturas e Sociedades da Universidade de Évora

\section{Referencia electrónica}

María Gloria de Antonio Rubio, «Recaudación real y prácticas de poder ejercidas en el siglo XV por recaudadores judíos en Galicia», Hamsa [En línea], 2 | 2015, Publicado el 31 diciembre 2015, consultado el 13 mayo 2021. URL: http://journals.openedition.org/hamsa/791 ; DOI: https://doi.org/ 10.4000/hamsa.791

\section{(c) (i) (9)}

Hamsa est mise à disposition selon les termes de la Licence Creative Commons Attribution - Pas d'Utilisation Commerciale - Pas de Modification 4.0 International. 


\title{
Recaudación real y prácticas de poder ejercidas en el siglo XV por recaudadores judíos en Galicia*
}

\author{
María Gloria de Antonio Rubio \\ CSIC-Xunta de Galicia \\ mgloria.deantonio@csic.es
}

\section{Resumo:}

Embora a legislação medieval do Reino de Castela proibisse aos judeus de exercer como recebedores de impostos, eram muitos os que, nomeados pelo próprio rei, praticavam essa atividade. Os cobradores judeus, como representantes do rei, tiveram o mesmo poder que os cristãos na cobrança e reclamação de tributos. Neste sentido, a Galiza não foi exceção. Na atualidade, constata-se o uso de mecanismos de poder, revelados de dois modos: o primeiro, quando o cobrador embarga ou leiloa bens pelo não pagamento da alcabala; o segundo, quando dois cobradores desafiam as autoridades municipais de Ourense.

Palavras-chave: Galicia, História Medieval, judeus, cobradores de imposto, alcabala.

\begin{abstract}
:
Although medieval legislation in Castilian kingdom forbade Jewish people to work as tax collectors, some of them, appointed by the king, practiced this activity. The Jewish collectors, as king's representatives, had the same power than the Christian ones for collecting and demanding taxes. In this sense, Galicia was not an exception. Currently there is evidence of the use of techniques of power revealed in two ways. The first one, when the tax collector confiscate or auction properties for the non-payment of the alcabala tax. The second one, when two tax collectors challenge the local authorities of Ourense.
\end{abstract}

Key words: Galicia, Medieval Legislation, Jews, collector, alcabala.

\section{Resumen:}

Aunque la legislación medieval en el reino de Castilla prohibió a los judíos trabajar como recaudadores de impuestos, fueron muchos los que, nombrados por el propio rey, practicaron esta profesión. Los recaudadores judíos, como representantes del rey, tuvieron el mismo poder que los cristianos para el cobro y reclamación de un tributo. En este sentido, Galicia no fue una excepción. En la actualidad, se tiene constancia del uso de mecanismos de poder que se muestran de dos maneras. La primera, cuando el recaudador embarga o subasta bienes por impago de la alcabala. La segunda, cuando dos recaudadores desafían a las autoridades municipales de Ourense.

Palabras clave: Galicia, legislación medieval, judíos, recaudador de impuestos, alcabala. 
El tiempo histórico denominado Baja Edad Media, en todos los países del Occidente europeo, se inició en los decenios comprendidos entre 1265 y 1325 y su término enlazó y se fundió con los primeros tramos de la modernidad, es decir, hasta 1520 aproximadamente. Los cambios económicos y políticos que tuvieron lugar durante este período repercutieron directamente sobre los sistemas de fiscalidad y cobro de rentas. Así, los primeros -cambios económicos- estuvieron relacionados con la depresión del siglo XIV que produjo grandes transformaciones en el sector primario, tanto en lo relativo a los regímenes de explotación de la tierra y de su propiedad, como a los tipos de productos cultivados y, sobre todo, a los procedimientos de comercialización. El auge de algunas actividades manufactureras y la mayor densidad de la actividad mercantil, en todos los niveles, explican el auge de procedimientos fiscales basados en la imposición indirecta sobre el comercio y el consumo. Los segundos cambios políticos- se refieren al primer desarrollo del Estado como forma de poder político y, con él, de la posibilidad de una fiscalidad nueva de las monarquías que superaba, sin anular, la anterior. Hubo, por lo tanto, una concentración de renta, obtenida mediante nuevos procedimientos, en beneficio del Estado monárquico, lo que le permitió aumentar sus campos de actividad y contribuir al mantenimiento del sistema social en sus estructuras básicas ${ }^{1}$.

En la fiscalidad castellana bajomedieval se distinguen dos períodos bien definidos. El primero abarca desde mediados del siglo XIII hasta la guerra civil de 1366-1369. Se caracteriza por el fuerte impulso inicial dado por Alfonso X (1252-1284) y se desarrolla a través de grandes altibajos, hasta conseguir la plena aparición de un nuevo sistema impositivo que culmina cuando se generaliza el cobro de la alcabala en los años cuarenta del siglo XIV. El segundo período corresponde a la época de la dinastía Trastámara (1369-1516) y en él no aparecen ya no era necesario- nuevos tipos de tributos pero se consolida el aparato legislativo e institucional de gestión de la Hacienda regia, que apenas había existido en el período anterior².

En el siglo XV, a efectos hacendísticos, el territorio del reino estuvo dividido en partidos y el peso principal de la gestión recayó sobre la Contaduría Mayor de Hacienda. Esta institución tuvo como misión el control sobre todos los ingresos y gastos, promover y organizar el cobro de las rentas y derechos, ordenar los pagos a realizar así como enviar los documentos hacendísticos pertinentes a la Contaduría Mayor de Cuentas para fiscalizar cómo se había realizado la administración de la Hacienda. Al frente de la Contaduría Mayor de Hacienda estaban los contadores mayores quienes tenían a sus órdenes otros contadores, que se solían llamar menores o de libro, especializados en diversas ramas de la función hacendística ${ }^{3}$.Los encargados de recibir el dinero debido por los arrendadores, concejo, aljamas, etc. fueron los recaudadores. Eran nombrados por el rey y situados en todos y cada uno de los partidos, pudiendo tener a sus órdenes otros recaudadores menores o locales. Desde el reinado de Juan Il el cargo de recaudador de cada partido o renta fue anejo al arrendamiento de la misma, con lo cual la institución quedaba integrada en la compleja figura del arrendador-recaudador, dos funciones que debían estar separadas pero que, a menudo, estaban unidas con lo que la Hacienda se ahorraba el salario del recaudador y pretendía simplificar el sistema de finanzas ${ }^{4}$.

\footnotetext{
* Este artículo ha sido ha sido desarrollado en el Instituto de Estudios Gallegos "Padre Sarmiento", dentro del proyecto Linaje, parentela y poder: la pirámide nobiliaria gallega (siglos XIII al XV) (II), dirigido por el Dr. Eduardo Pardo de Guevara. Financiado por Ministerio de Economía y Competitividad, Programa Estatal de Fomento de la Investigación Científica y Técnica de Excelencia, Subprograma Estatal de Generación de Conocimiento. Ref. HAR2013-42985-P.

${ }^{1}$ Miguel Ángel Ladero Quesada, Legislación hacendística de la corona de Castilla en la Baja Edad Media, Madrid, Real Academia de la Historia, 1999, pp. 9-10.

2 Miguel Ángel Ladero Quesada, Fiscalidad y poder real en Castilla (1252-1369), Madrid, Universidad Complutense, 1993, pp. 13-14.

${ }^{3}$ Miguel Ángel Ladero Quesada, La Hacienda real de Castilla en el Siglo XV, La Laguna, Universidad de La Laguna, 1973, pp. 18-19, 21.

${ }^{4}$ M. Á. Ladero Quesada, La Hacienda real..., pp. 21-22.
} 
La figura del arrendador nace del sistema más frecuente del cobro de rentas: el arrendamiento. Es decir, las rentas se traspasaban a las personas o grupos que pagaban al monarca un precio por ellas, fijado en subasta, y que corrían con todos los avatares y ventajas del cobro. Su beneficio consistía en la diferencia entre lo que efectivamente cobraban y lo que se habían comprometido a pagar al rey por la renta. Para éste era la forma de obtener seguridad e incluso ingresos anticipados, a cambio de renunciar a una parte de lo que podía haber obtenido si hubiese organizado directamente el cobro de la misma. Las cantidades de cobro previstas en cada arrendamiento partían de un conocimiento previo por parte de la Contaduría Mayor del valor aproximado que podía pedirse por una renta en cuestión, lo que se lograba a través de los informes facilitados obligatoriamente por anteriores arrendamientos y de los conseguidos por los mismos oficiales de la Contaduría. Se arrendaban públicamente, por pregones y una vez pregonada la almoneda los contadores mayores de Hacienda y, potestativamente, otros altos cargos de la corte iban recibiendo o rechazando los diferentes precios ofrecidos por los licitantes, hasta efectuar el remate de la subasta a favor del más adecuado. Una vez rematada la renta, el arrendador tenía de plazo normalmente entre diez y veinte días para contentar de fianzas, es decir, presentar fiadores que garantizasen a la Hacienda contra el incumplimiento de sus obligaciones, volviendo a ser subastada la renta si no eran presentadas. Una vez admitidos los fiadores, el arrendador recibía una carta de recudimiento que le daba poderes suficientes para proceder al cobro de la renta.

El papel de algunos judíos como arrendadores fue, por lo que parece, importante y continuo. No solían actuar en solitario sino que, habitualmente, pertenecían a varios círculos familiares o de relación profesional muy restringidos en relación con el conjunto mismo de la comunidad judía. Tal vez por eso podían ser imprescindibles y resistir sin gran merma tanto las condenas teóricas a su actividad como las presiones políticas destinadas a combatirla ${ }^{6}$.

En el primero de ambos aspectos hay que situar la consideración general que recoge el Código de las Siete Partidas al condenar que los judíos puedan tener poder sobre los cristianos por lo que no deberían ser cogedores de rentas y derechos reales": "que ningund judío nunca ouiese jamás lugar honrrado, nin oficio público con que pudiesse apremiar a ningund christiano en ninguna manera" ${ }^{8}$. Prohibición que no era nueva en la legislación castellana puesto que había sido recogida en la de siglos anteriores. La del S. XII, concretamente, aunque fue permisiva en lo referido al reconocimiento de la religión judía y al funcionamiento interno de las aljamas, señaló fuertes cortapisas a la convivencia entre cristianos y judíos, entre ellas, la prohibición del ejercicio de oficios y cargos públicos que llevaran aparejada jurisdicción sobre cristianos ${ }^{9}$. En la legislación posterior se radicalizaron las posturas y a principios del S. XV la prohibición de ejercer ciertas profesiones tenía una clara intención segregacionista y discriminatoria al impedir a los judíos ejercer, entre otras, la medicina, en cualquiera de sus ramas, el comercio, así como el arrendamiento y recaudación de rentas ${ }^{10}$. Por su parte, la

\footnotetext{
${ }^{5}$ M. Á. Ladero Quesada, La Hacienda real..., pp. 22-26.

${ }^{6}$ M. Á. Ladero Quesada, Fiscalidad y poder real..., pp. 258-261.

${ }^{7}$ M. Á. Ladero Quesada, Fiscalidad y poder real..., p. 261.

${ }^{8}$ José María Monsalvo Antón, Teoría y evolución de un conflicto social. El antisemitismo en la Corona de Castilla en la Baja Edad Media, Madrid, Siglo XXI de España editores, 1985, p. 148.

9 Enrique Cantera Montenegro, “Cristianos y judíos en la meseta Norte Castellana: la fractura del siglo XIII" en Yolanda Moreno Koch y Ricardo Izquierdo Benito (Coords.), Del pasado judío en los reinos medievales hispánicos: afinidad y distanciamiento. XIII Curso de Cultura Hispanojudía y Sefardí de la Universidad de Castilla-La Mancha, Cuenca, Ediciones de la Universidad de Castilla-La Mancha, 2005, pp. 4588.

10 “(...) Que ninguno nin algunos judíos nin judías, nin moros nin moras non sean arrendadores, nin procuradores, nin almojarifes, nin mayordomos, nin arrendadores de las mis rentas, ó de otro Sennor ó Señora, nin cristiano nin cristiana; nin usen de alguno dellos los cristianos é cristianas, nin entrellos; nin sean correedores ó correedoras [...] é qualquier judío ó judía, ó moro que contra esto viniere, al contrario faciendo ó contra cosa alguna dello, que paguen en pena por cada vegada dos mill
} 
doctrina oficial de la Iglesia, plasmada en las disposiciones y constituciones de los concilios provinciales, está estrechamente ligada a la postura de las más altas jerarquías de la Iglesia de Roma. El concilio provincial de Zamora de 1312 sentó unas bases que se repetirán después. Entre ellas, no otorgara los judíos ningún oficio ni dignidad pública: "es que daquí adelante non tengan offiçios nin dignidades de Reyes, nin de otros Príncipes seglares qualesquier, et dexen las que tienen fasta el término sobredicho". Idea que se repite diez años después, en el Concilio de Valladolid:

Queriendo cortar de raíz la absurda e irracional corruptela que redunda en aprobio y detrimento de la fe christiana, en virtud de la cual y contrariando las sanciones canónicas, los judíos y sarracenos son preferidos en los destinos públicos a los christianos, mandamos a todos los prelados de Iglesias, recordándolos el juicio divino, que cuiden de que inviolablemente se observen bajo pena de escomunión y aplicación de otras, los estatutos de los Santos Padres promulgados acerca de este particular ... ${ }^{11}$.

Las presiones políticas se manifiestan en la reiterada denuncia en las Cortes contra la presencia de judíos en las finanzas reales. De manera que la petición de que se prohibiera a los judíos ocupar cargos en la Corte o ser oficiales del rey fue una de las más repetidas, lo que muestra, según diversos autores, un creciente sentimiento antijudío aunque sus destinatarios eran sólo un grupo de hebreos potentes económicamente. En las Cortes de 1288, Sancho IV promete no hacer a ningún judío cogedor, sobrecogedor, recaudador o arrendador de ningún pecho o servicio, prohibición que se repite en lasde los años 1295, 1302, 1305, 1313-en las que se extendió la demanda de alejamiento de judíos de cualquier oficio de la casa del rey o de sus tutores-, 1317, 1329, 1371, 1380, 1385 y $1464^{12}$.Sin embargo, prácticamente todos los reyes se sirvieron de judíos y las medidas tomadas en la Cortes, y aprobadas por los propios monarcas, no fueron nunca puestas en práctica de un modo absoluto. Por lo tanto, la asignación de rentas a judíos no se correspondió, de manera alguna, con una decisión personal del monarca para colocarlos en altos cargos y construir sobre ellos los cimientos de la organización económica, fiscal, y, en consecuencia del reino, sino que obedeció, exclusivamente, a la capacidad económica de los mismos y a su disponibilidad económica para ofrecer la puja más alta por un tributo en subasta pública.

Fiscalmente, Galicia, como parte de la corona Castilla, respondió al mismo patrón que el resto del reino. Se organizó en cuatro partidos fiscales principales en orden al pago de impuestos: Santiago con Tuy, Lugo, Orense y Mondoñedo pero, durante los años ochenta, las villas de Sarria y Vivero con sus respectivos términos se constituyeron como partidos fiscales independientes. Por lo general, los límites de cada uno de estos partidos coincidían con aquellos que marcaban la distribución eclesiástica de la época. Pero no siempre fue así y, en ocasiones, las rentas de algunas villas y lugares formaron parte de un partido fiscal distinto a la diócesis a la que pertenecía. Tal es el caso de las rentas del partido de Ribadavia, perteneciente a la diócesis de Tuy, cuyas rentas se arrendaban con las del partido fiscal de Orense ${ }^{13}$.

Uno de los tributos reales mejor documentados en Galicia fue la alcabala. Ésta tuvo su origen en 1342 cuando las Cortes autorizaron a Alfonso XI su cobro durante tres años para sufragar los gastos generados por el sitio de Algeciras. En los años siguientes los Procuradores de Cortes continuaron autorizando el cobro provisional de alcabalas, tratando de evitar su conversión en renta habitual. Sin embargo, desde el año 1429 se confirma su existencia como

maravedís..."- José Amador de los Ríos, Historia Social Política y Religiosa de los judíos de España y Portugal, Valencia, Librerías París-Valencia, 1994,tomo II, p. 621. Edición Facsímil.

11 J. M. Monsalvo Antón, Teoría y evolución ..., p. 154.

12 M. Á. Ladero Quesada, Fiscalidad y poder real ..., pp. 261-262; J. M. Monsalvo Antón, Teoría y evolución..., pp. 172-173.

${ }^{13}$ Amparo Rubio Martínez, Hacienda y Gobierno de los Reyes Católicos en Galicia, Madrid, Universidad Complutense de Madrid, tesis doctoral inédita, 2007, p. 7. 
tributo fijo y ordinario. El cambio debió ocurrir durante el reinado de Enrique III ya que desde el año 1393 no aparece ninguna noticia sobre la concesión de alcabalas al monarca. La alcabala, durante el siglo XV, gravó en un $10 \%$ el valor de las compraventas y trueques que se efectuaban en la corona de Castilla. Inicialmente era pagada entre el vendedor y el comprador pero, a partir del reinado de Enrique III, se hace el vendedor cargo por completo de su pago. Como impuesto indirecto sobre el consumo debía ser pagada tanto por pecheros como por nobles y clérigos sin excepción, salvo aquellos privilegios particulares que se registraban en los cuadernos de alcabalas ${ }^{14}$.

Su recaudación por judíos se documenta en Galicia entre 1422 y $1491^{15}$ y, como característica particular es necesario destacar que estos no fueron naturales de la zona afectada por el tributo-procedían de Astorga y Cacabelos (León), Hita (Guadalajara), Villalón de Campos (Palencia) o Madrid- pero, en ocasiones, llegaron a adquirir la condición de vecino ${ }^{16}$. Sirva como ejemplo el caso de Abrahán Cominero de Villalón admitido por el concejo de Ourense como vecino por cinco años, en $1446^{17}$. Todos ellos tuvieron acceso, en igualdad de condiciones que los cristianos, a los recursos legales previstos para el cobro de tributos reales y utilizaron todos los resortes de poder que su cargo les confería para ejercer su profesión como representantes del rey. Este ejercicio de poder se manifestó fundamental, pero no exclusivamente, de dos maneras: la primera, en las figuras de Judá Pérez ${ }^{18}$ y Mosé Pérez ${ }^{19}$, recaudadores, entre otras rentas, de las alcabalas de Ourense, y en su negativa a aceptar la orden del concejo de esa ciudad para trasladarse a vivir a la judería tras la orden de apartamiento de 1480.La segunda, en el uso del sistema judicial establecido para cobrar las cantidades debidas en igualdad de condiciones que los cristianos.

De la vida personal de Judá y Mosé Pérez poco es lo que se conoce salvo que fueron hermanos, que ambos estuvieron casados y fueron padres de varios hijos. Originarios de Astorga, vivieron en Ourense donde adquirieron categoría de vecinos ${ }^{20}$. Mosé tuvo su residencia en una casa situada en la "Praça do Canpo" ${ }^{\text {"21 }}$, actual Plaza Mayor, considerada ya en el año $1448^{22}$ como una de las mejores plazas de la ciudad tanto por su tamaño y su capacidad para exponer mercancías como por su seguridad. La vida profesional de los dos hermanos estuvo relacionada con las finanzas, la administración de casas señoriales y con la recaudación de tributos. Concretamente, de la alcabala de Ourense y su obispado entre 1484 y 1488 y de la del obispado de Ourense, Lugo y Mondoñedo en $1489^{23}$.

Su vida personal y profesional se vio afectada por la orden de apartamiento decretada, en 1480, por los Reyes Católicos en las Cortes de Castilla reunidas en Toledo. En ella, e invocando motivos puramente religiosos, se ordenó separar, en un plazo máximo de dos años, todas las juderías castellanas a lugares que, rodeados de cerca, garantizasen la conveniente separación

\footnotetext{
${ }^{14}$ A. Rubio Martínez, Hacienda y Gobierno..., pp. 73-75.

${ }^{15}$ María Gloria de Antonio Rubio, Los judíos en Galicia (1044-1492), A Coruña, Fundación Pedro Barrié de la Maza, 2006, pp. 174-189.

${ }^{16}$ La vecindad derivaba del nacimiento en la población o de la habitación en ella por cierto tiempo, acompañadas estas condiciones de ser propietario en el lugar de bienes inmuebles y de la admisión como vecino por el Concejo, y suponía para el vecino la protección del fuero local, el disfrute de los bienes comunales y la participación en gobierno municipal. Luis García de Valdeavellano, Curso de historia de las instituciones españolas, Madrid, Alianza Universidad textos, 1992, p. 543.

${ }^{17}$ M. G. de Antonio Rubio, Los judíos en Galicia..., pp. 492-493, doc. 188.

${ }^{18}$ María Gloria de Antonio Rubio, Judíos e Inquisición en Ribadavia, Ribadavia, Concello de Ribadavia, 2009, pp. 77-82.

${ }^{19}$ M. G. de Antonio Rubio, Judíos e Inquisición..., pp. 82-86.

${ }^{20}$ Idem, pp. 565-566, doc. 273.

${ }^{21}$ Xesús Ferro Couselo, A vida e a fala dos devanceiros, Vigo, Galaxia, 1996, tomo II, pp. 238-240, doc. 223. Edición Facsímil.

${ }^{22}$ X. Ferro Couselo, A vida e a fala ..., tomo II, pp. 142-144, doc. 136.

${ }^{23}$ M. G. de Antonio Rubio, Los judíos en Galicia..., pp. 188-189.
} 
entre fieles e infieles. Se prohibió a los judíos tener casa fuera de la judería, contratar mercaderías en fiestas cristianas, o salir a dormir fuera del barrio que les había sido asignado. No se les restó, sin embargo, ninguna libertad de movimientos, ni siquiera la facultad que tenían de poseer tiendas en la plaza del mercado o en las calles cristianas ${ }^{24}$.

En Ourense, el primer requerimiento para "guardar la Ley de Toledo" se produjo el 3 de julio de $1484^{25}$, dos años después de finalizar plazo máximo establecido por los reyes. En ese día se reunieron en la sinagoga el juez, el procurador de la ciudad y cinco judíos a los que les comunicaron que en tres días se les asignaría el lugar que a partir de ese momento sería la judería. Sin embargo, o nunca se delimitó la zona o, si se hizo, no se llevó a cabo el traslado, pues el 22 de mayo de $1487^{26}$, tres años después, las autoridades municipales ordenaron que los judíos se fueran a vivir a la "Rúa Nova da dita çibdad, junto da porta da vyla, de hua parte e da outra, e lles dese e asynalase casas en que morasen". En esta ocasión el apartamiento había perdido el carácter de trámite que parecía tener el primer intento por dos razones: la primera, se indicaron las casas a las que tendrían que trasladarse cada uno de los judíos de la ciudad, siendo necesario, en algunos casos, desalojar a sus propietarios cristianos. La segunda, la actitud de los nuevos jueces quienes manifestaron su deseo y satisfacción de que los judíos fueran apartados: "e os ditos juises diseron que lles plasía e eran muy contentos de lles yr faser o dito mandamento pera que fesesen o dito apartamento".

En consecuencia, el 22 de mayo de 1487, como al resto de los judíos de la ciudad, a Judá y Mosé les asignaron una vivienda en la judería. A Judá se le adjudicó una casa propiedad de María Casada y, aunque se desconoce el propietario de la adjudicada a Mosé, se sabe que no estuvo de acuerdo con ella porque respondió a las autoridades municipales diciendo que apelaría a la justicia real para que le dieran un lugar conveniente donde vivir y no se cometieran injusticias con él.

La amenaza o apelación debió surtir efecto puesto que unos meses después, el 28 enero de $1488^{27}$, fue requerido, de nuevo, para que se trasladase a la casa de Aldara González. Sin embargo, tampoco obedeció esta segunda orden puesto que el 6 de noviembre de $1488^{28}$, aún vivía en su casa de la plaza del Campo. En este día y en su propia casa, estando presente también su hermano Judá, las autoridades municipales les asignaron dos nuevas casas: la de Gonzalo de Puga, regidor, y la del abad de San Esteban de Ribas de Sil. Esta vez bajo amenaza de las penas previstas en la ley, lo que no impidió que ambos hermanos mantuvieran su negativa al traslado alegando dos motivos:

El primero, que ya no eran vecinos de Ourense y que, por lo tanto, no estaban obligados a obedecer a las autoridades municipales. Judá afirmó que estaba avecindado en Villafranca del Valcárcel donde hacía 15 meses que se había trasladado, coincidiendo casi con el primer requerimiento datado el 22 de mayo de 1487 . Mosé alegó que hacía casi un año que se había ido a vivir a Allariz, es decir que se habría marchado en torno a noviembre de 1487 y el segundo requerimiento fue hecho el 28 enero de 1488. Es decir, ambos habían abandonado su condición de vecinos de Ourense y salido de la ciudad con "muger y hijos y hasienda" en fechas muy próximas a la llegada de las autoridades reales y a la fecha del segundo requerimiento.

El segundo motivo que ambos hermanos alegaron para no obedecer las órdenes de apartamiento fue que el objetivo de su estancia en Ourense era poner a buen recaudo la recaudación de las alcabalas y que no tenían intención de morar o de ser vecinos de la ciudad por lo que afirmaron no estar "obligados de bibyr en apartamiento ni judería, como lo son los

\footnotetext{
${ }^{24}$ Luis Suárez Fernández, Documentos acerca de la expulsión de los judíos, Valladolid, Consejo Superior de Investigaciones Científicas, 1964, pp. 31-32.

${ }^{25}$ X. Ferro Couselo, A vida e a fala..., tomo II, p. 233, doc. 218.

${ }^{26}$ X. Ferro Couselo, A vida e a fala..., tomo II, pp. 235-237, doc. 222.

${ }^{27}$ Idem tomo II, pp. 235-237, doc. 222.

${ }^{28}$ Idem, tomo II, pp. 238-240, doc. 223.
} 
vecinos de ella" y que, por lo tanto, no habían incurrido en las penas previstas en la ley. Es más, exigieron a las autoridades que cumplieran con la ley "del Quaderno" en lo que a las condiciones de alojamiento de los recaudadores se refería, facilitándoles el acceso a una casa gratis y segura donde no estuvieran en peligro ni el dinero ni ellos mismos, tanto si estaba en la judería como si no. Les comunicaron, asimismo, su intención de querellarse ante el gobernador de Galicia, no sólo por el requerimiento de apartamiento sino por las amenazas que ellos mismos y los judíos que les tenían arrendadas las rentas habían sufrido. Para ello les requirieron para que comparecieran con ellos en 10 días ante Sancho Ruys de Villegas para que éste determinase. Solicitaron, además, al notario, Juan García, que incluyeran su respuesta junto al requerimiento y que les diese copia del mismo.

Es decir, en su calidad de recaudadores, a pesar de que legalmente les estaba prohibido ejercer como tales, gozaron de todos los poderes que llevaba aparejados la figura del recaudador-arrendador real lo que les permitió no obedecer a las autoridades municipales recurriendo a instancias superiores. Sin embargo, en su calidad de vecinos y, previsiblemente, para evitar el traslado a la judería, habían optado por abandonar la vecindad de Ourense y trasladarse a Villafranca de Valcárcel, en el caso de Judá, y a Allariz, en el caso de Mosé.

La segunda forma en la que se manifestó el poder de los recaudadores judíos, tal y como se ha mencionado anteriormente, fue en el uso del sistema judicial cristiano, en igualdad de condiciones, para reclamar las cantidades debidas por impago de tributos, tanto si el deudor era cristiano como si era judío.

El primer paso para exigir la cantidad debida por un tributo era la reclamación de la deuda a la que seguía, en caso de persistir en el impago, el embargo o entrega de bienes y su posterior venta en subasta pública para convertirlos en dinero. Aunque la documentación conservada no muestra ningún proceso completo, éste se puede intuir gracias a procesos parciales. De este modo, se tiene constancia no sólo de reclamaciones a instituciones, como por ejemplo al concejo de A Coruña, sino de reclamaciones a recaudadores menores o fiadores

Un ejemplo del primer caso es el requerimiento llevado a cabo por el procurador de los arrendadores mayores, el 9 de Diciembre de $1435^{29}$, contra el concejo de A Coruña, para que pagase a Abrahán Benbeniste 3.000 maravedíes que le debía de la renta de las albaquías ${ }^{30}$ :

... commo so procurador sostituto que es, e mostro e presento un escripto de demanda, estando presente el dicho Gonçalo Medes en nonbre del dicho conçejo... e los dichos tres mill maravedies mandan de los dar e pagar a don Abrahen Vienbeniste, asy como al thesoreiro de la dicha renta. $E$ sobre esto vos pido conplimiento de justiçia ...

La reclamación de otros impuestos reales siguieron el mismo procedimiento que las alcabalas pero están menos documentados. Es el caso de la solicitud de Judá Pérez al concejo de Ourense, el 6 de Marzo de $1432^{31}$, para que le pagase los maravedíes que le debía del yantar -deber anejo al del hospedaje y que obligaba a sustentar al señor y sus enviados mientras permanecieran en la casa y que podía ser redimida en metálico ${ }^{32}$-, petición a la que accedió el concejo.

\footnotetext{
${ }^{29}$ M. G. de Antonio Rubio, Los judíos en Galicia..., pp. 435-436, doc. 140.

${ }^{30}$ Albaquía: impuestos que se deben a la monarquía de años pasados y que la Hacienda real los arrienda por periodos concretos. Por ejemplo, en 1480 se arrendó lo correspondiente al periodo 1453-1477 Amparo Rubio Martínez, "Los agentes fiscales del reino de Galicia a fines del siglo XV" en A. Borrero Fernández; J. Carrasco Pérez y R. G. Peinado Santaella (Eds.) Agentes de los sistemas fiscales en Andalucía y los reinos hispánicos (siglos XIII-XVII): un modelo comparativo, Madrid, Instituto de Estudios Fiscales, 2014, pp. 117-143, p. 122 y "Un hombre de negocios a fines del siglo XV: el notario santiagués Lope Gómez de Marzoa" en Actas del Simposio Poder, Fisco y Mercado; la ciudad y sus redes en la Baja Edad Media, celebrado en la Fac. de Letras de la UPV, Ediciones de la UPV, 2015, (en prensa), p. 5.

${ }^{31}$ M. G. de Antonio Rubio, Los judíos en Galicia..., p. 397, doc. 50.

${ }^{32}$ L. García de Valdeavellano, Curso de Historia ..., p. 252; M. Á. Ladero Quesada, Fiscalidad y poder real..., p. 37.
} 
El segundo caso, la reclamación a un recaudador menor, se documenta, por ejemplo, el 17 de abril de $1449^{33}$. En esta fecha, Abrahán Cominero, en nombre de Diego Álvarez Galdín, recaudador de las alcabalas del obispado de Ourense de 1445, demandó a "Fernan Cordo, Estevo de Barreiro" y a "Estevo Gonsales" la cuantía de "mil dineros de brancas" en razón de la alcabala que de él habían arrendado. Éstos respondieron diciendo que ya habían pagado las cantidades acordadas y que la cantidad requerida no figuraba en la obligación con ellos contraída.

Asimismo, en Ourense, se documenta en el año 1433 la reclamación de Judá Pérez a un fiador. En la documentación de esta ciudad el nombre Judá Pérez se registra desde 1423 hasta 1497 , en este momento ya convertido al cristianismo. Un período de ejercicio profesional tal largo y con lapsos de tiempo, en los años centrales del siglo, sin ninguna actividad, solo puede indicar que se trata de dos personas diferentes. De este modo el primer Judá Pérez, en virtud del poder recibido por Fernando García de Astorga, solicitó que se le permitiese arrendar las rentas correspondientes al año $1433^{34}$. Sin embargo, debió tener dificultades para cobrarlas porque el 29 de diciembre ${ }^{35}$, el procurador del concejo, Pascual Rodríguez, le requirió para que arrendase las alcabalas. En caso contrario, los regidores pondrían fieles para que no se perdiesen las cantidades correspondientes. Como respuesta, Judá Pérez solicitó que se tomasen bienes de todas las personas en las que él había rematado las alcabalas y que no habían pagado las fianzas correspondientes:

... en as casas de Yudá Peres, recaudador, estando el y presente o dito Yudá Peres, paresçeu y ante él Pascoal Rodrigues, procurador do conçello, e tomou testimonio contra el e que lle requería que, por razon que él tiña posta as rendas de noso señor El Rey en almomeada deste dito ano de XXXIII anos e lle era dito que as tina rematadas, por ende que lle requería se era contento dos ditos alcaualas e de as arrendar, senón que os rejedores que porían fiees en tal maneira que as alcaualas do dito señor Rey non se perdesen, senón que protestaua que a culpa fose do dito Yudá Peres etc. Et logo o dito Yudá Peres diso que as tina postas e arrendadas et rematadas en çertas personas, vesinas desta çidade, e que, se lle non desen fianças, que requerería aos ditos juises que os prendasen, porlo qual non era neçesario que se posesen fyees etc. I o dito Pascoal Rodrigues pedío asy signado etc ...

Si la reclamación no surtía el efecto deseado los recaudadores recurrieron al embargo o la entrega de bienes. El embargo, en términos jurídicos, se define como la retención de bienes por mandamiento de juez o autoridad competente con el objetivo de obtener con su venta la cantidad reclamada. Así, el 5 de Noviembre de $1484^{36}$, Judá Pérez solicitó ante el alcalde de Ourense y el bachiller "Fernán Yanes de Castro", la ejecución de los bienes de "Fernández de Ceya" como fiador de "Pedro de Paaço" y "Alvaro de Soto", por los 5.000 maravedíes correspondientes a la alcabala de "a Costa de Sadur e Terra de Sayane" de 1484 y por el mismo concepto, a "Vasco de Seixas" como fiador de las alcabalas de "San Jurjo e Santa Locaya", por valor de 3.600 maravedíes. Petición que fue atendida por el alcalde al ordenar el embargo de los bienes de ambos fiadores. Según el sistema general de arrendamiento, los fiadores eran los encargados de garantizar a la Hacienda regia el cumplimiento de las obligaciones contraídas por el arrendador y como, en esta ocasión, no se recaudó la cantidad acordada, los fiadores tendrían que haber pagado, de su propio dinero, la diferencia entre lo acordado y lo recaudado. Sin embargo, no debieron hacerlo, por lo que Judá Pérez, solicitó el embargo de sus bienes.

\footnotetext{
${ }^{33}$ M. G. de Antonio Rubio, Los judíos en Galicia..., pp. 496-497, doc. 196.

${ }^{34}$ X. Ferro Couselo, A vida e a fala ..., tomo II, p. 226, doc. 208.

${ }^{35}$ Idem, tomo II, pp. 226-227, doc. 209.

${ }^{36}$ Idem, tomo. II, p. 234, doc. 221.
} 
Un ejemplo de ejecución de un embargo, aunque en este caso concreto no derivado del pago de tributos pero que muestra claramente como era el procedimiento, se recoge en el año $1432^{37}$ :

En este dia e ora, e por estas testimuñas e por los ditos juises, Diego Ferrandez, pregoeiro, fiso venda et remataçion de [en blanco] botoos e doas de prata, que pesaron [en blanco] et rayas, en Braan de Lion por XIII brancas cada rayal, a pedimiento do dito Pascual Rodriguez, procurador. E diso, o dito pregoeiro, que frontara con as ditas prendas a moller de Gomez de Chantada a pedimento do dito Pascual Rodriguez. E deu o dito pregoeiro preçeo de terçio dia en que as rem [...] a sen dapno. Testimuyas: os ditos juises e mays sobreditos.

La mujer de Gómez de Chantada había dejado en prenda de un pago unas piezas de plata y una cantidad no determinada de "rayas" de plata. En el plazo fijado no pagó la cantidad acordada y el procurador Pascual Rodríguez sacó a subasta la plata para, de este modo, recuperar o conseguir el dinero. Se puede suponer que, dado que es el procurador del concejo el que promueve la venta, la cantidad debida estaría relacionada con algún tipo de pago al concejo. La subasta de la plata dada en garantía, se comunicó a todos los habitantes de Ourense a través del pregonero para que pudieran pujar $y$, posteriormente para que todos tuvieran conocimiento del hecho de que Abrahán de León había sido el que había pujado más altoy, por lo tanto, la plata pasaba a ser de su propiedad: "fiso [...] rematación [...] en Braan de lion", habiendo obtenido XIII blancas por cada "raya" de plata.

La alternativa al embargo fue la entrega de un bien para el pago de una deuda o tributo. Con la entrega del bien se cumplía con la obligación de pago, sin que el que lo entregaba pudiera recuperarlo -lo que lo diferenciaba de la prenda- pero, también sin que el que lo recibía pudiera reclamar si al venderse el bien se obtuviera un valor inferior a la deuda inicial, lo que lo diferencia del embargo. Sirva como ejemplo la entrega realizada el día 11 de septiembre de $1451^{38}$, por el procurador del concejo de Ourense a Judá Pérez en pago de los pedidos, el más antiguo de los impuestos reales extraordinarios que solía gravar con un $10 \%$ los bienes de todos aquellos obligados a pagarlo ${ }^{39}$ :

\section{Prendas de pedidos}

Anno de $\mathrm{LI}$, a XI de setembre, en Orense, Diego de Balboa, procurador do concello, entregou a Yuda Peres por CCCC XX IIII dineros, estas prendas de Vasco Peres: hunn manto e hunns mantos grandes pretos, et hunn retallo de panno pardillo [...do] todo por los ditos XXIIII dineros.

Es decir, el procurador del concejo entregóal recaudador Judá Pérez como pago de los pedidos correspondientes al año 1451, varias prendas de ropapor valor de 124 dineros.

Los bienes conseguidos de una manera o de otra eran puestos en subasta pública para convertirlos en efectivo. Este procedimiento queda claramente reflejado 13 de Febrero de $1432^{40}$, en el que el alcalde de Ourense, mediante sentencia, ordenó que de los 50 maravedíes que se habían obtenido por la venta de una "tinalla"que había pertenecido a "Alonso Sordo", cuarenta fueran para pagar el pedido y diez para la alcabala que éste debía a Abrahán de León. Manteniendo, además, a este último el derecho a embargar otros bienes del deudor para el cobro de los maravedíes que aún le debía.

Algo muy parecido debió ocurrir en $1447^{41}$ cuando se remataron, es decir, se subastaron y vendieron, 13 prendas por las deudas correspondientes al impago de ciertas cantidades del pedido de la rúa de los Zapateros. Entre las piezas subastadas se encontraba la perteneciente a la mujer de "Isaque vello", por la que se obtuvieron 10 dineros:

\footnotetext{
${ }^{37}$ M. G. de Antonio Rubio, Los judíos en Galicia..., p. 399, doc. 55.

${ }^{38}$ M. G. de Antonio Rubio, Los judíos en Galicia..., p. 510, doc. 209.

${ }^{39}$ Idem, p. 81.

40 Idem, p. 397, doc. 49.

${ }^{41}$ Idem, p. 493, doc. 189.
} 
Anno de IIIL annos, a nove dias do mes de Janeiro, foron rematadas prendas que se sigen por lo dito pedido da rrua dos çapateiros. Primeramente ...

- Jaque Vello de ssua moller de [rrenna] Canes, por X .- logo foy tirado ...

Otro ejemplo del mismo procedimiento es la venta de una casa de don Zulema Abenarroyo, miembro de la Cámara de Cuentas de la Cancillería Real ${ }^{42}$, recaudador del reino de Galicia desde 1396 a 1400 y, desde 1402, sin especificarse hasta cuando, del arzobispado de Santiago y Tui, según se desprende de un documento fechado el 8 de abril de $1424^{43}$ :

\begin{abstract}
Alfonso López de Valladolid, tesorero real de los alcances y albaquías, vende judicialmente una casa que había tenido en Torrijos, don Çuleman Abenarroyo, para cobro de las deudas que había dejado pendientes al rey. Se inserta cédula de Juan II a los tenedores de bienes que fueron de don Çuleman Abenarroyo, recaudador del reino de Galicia desde 1396 hasta 1400 y desde 1402 recaudador del arzobispado de Santiago y Tuy, ordenando que entreguen esos bienes a Alfonso López, para devolver en la recaudación. Hay otra carta real a los tesoreros y recaudadores, para que entreguen a Alfonso López los mrs. de oro, plata, aceite, pan, vino, seda y lana de la recaudación.
\end{abstract}

El último paso del proceso de reclamación de deudas era la cárcel para el deudor. La documentación gallega ofrece un caso singular en el que uno de los recaudadores de Ourense, Abrahán de León, ya mencionado en anteriores ocasiones, es sentenciado a prisión, por cuarenta maravedíes que debía de los pedidos. Sin embargo, como era persona importante, los mismos jueces que le condenaron solicitaron que se prendiera a algún otro vecino de la ciudad. Esta práctica de apresar a unas personas en nombre de otras se documenta, de nuevo, el 5 de Octubre de $1449^{44}$, en la carta que el concejo de Ourense dirige a la abadesa de Santa Clara de Allariz. El motivo de la misma era solicitar la puesta en libertad de varios vecinos de la ciudad que estaban presos en el castillo de Allariz por las deudas que Abrahán Cominero tenía con el convento, derivado también de la recaudación de tributos reales:

Ben sabedes como nosos vesiños están presos con outros vasallos de noso senor obispo en ese castello d'Allaris, a qual prijón foy feita por voso mandado, disendo que vos deuía Abraán Cominero çertos mrs de çertos libramentos de noso sennor El Rey, aos quaes nos non éramos nen somos obrigados nen sabemos qué cousa he...

Por tanto y a modo de conclusión se puede afirmar que en la Edad Media y especialmente en el siglo XV, los judíos del reino de Castilla ejercieron como arrendadores y/o recaudadores de tributos reales, a pesar de que tanto en la legislación civil como en la eclesiástica lo tenían prohibido. Prohibición basada en el poder que el ejercicio de esta profesión les confería sobre los cristianos. A pesar de ello, los reyes les permitieron arrendar sus rentas, lo que no significa que tuvieran intención de colocarlos en puestos clave de la organización fiscal sino que fueron compañías judías o individuos aislados los que, en un momento determinado, ofrecieron una mayor cantidad de dinero por el tributo en cuestión. Esto fue posible porque la mayoría de las rentas reales se adjudicaban en subasta pública, es decir, la obtenía aquel que pujaba más alto por ella, independientemente de su religión. Una vez obtenida una renta, los judíos pudieron utilizar, sin ningún tipo de discriminación religiosa y en igualdad de condiciones que los cristianos, todos los recursos legales necesarios para el cobro y, en su caso, la reclamación del tributo arrendado. En este sentido Galicia, excepto por la escasez de fuentes documentales y

\footnotetext{
42 Yitzhak Baer, Historia de los judíos en la España Cristiana, Barcelona, Riopedras ed., 1998, tomo II, p. 401.

43 Pilar León Tello, Judíos de Toledo, inventario cronológico de documentos, Consejo Superior de Investigaciones Científicas, Instituto "B. Arias Montano", 1980 tomo II, pp. 226-227, doc. 758.

${ }^{44}$ X. Ferro Couselo, A vida e a fala..., tomo II, pp. 296-297, doc. 277.
} 
por el lugar de origen de los arrendadores/recaudadores -nunca gallegos-, no presenta ninguna particularidad que la distinga del resto del reino en lo que respecta al ejercicio del poder anejo a estas profesiones. Ejercicio que se manifiesta tanto en la utilización de los recursos que la legislación ponía a su disposición para el cobro de las rentas y, en caso de impago, reclamación de las mismas, como en el desafío de Judá y Mosé Pérez a las autoridades orensanos cuando éstas ordenaron su traslado a la judería en cumplimiento de la orden de apartamiento de 1480 . 